\title{
Observation of Whole Flushing Process of a River Sand Bar by a Flood Using X-Band Radar
}

\author{
Satoshi Takewaka \\ Division of Engineering Mechanics and Energy, University of Tsukuba, Tsukuba, Ibaraki 305-8573, Japan; \\ takewaka@kz.tsukuba.ac.jp; Tel.: +81-29-853-5361; Fax: +81-29-853-5207 \\ Academic Editor: Gerben Ruessink \\ Received: 25 December 2015; Accepted: 18 April 2016; Published: 4 May 2016
}

\begin{abstract}
Morphological changes during a flood event in July 2010 were observed with X-band marine radar at the mouth of Tenryu River, Shizuoka, Japan. Radar images were collected hourly for more than $72 \mathrm{~h}$ from the beginning of the flood and processed into time-averaged images. Changes in the morphology of the area were interpreted from the time-averaged images, revealing that the isolated river dune was washed away by the flood, the width of the river mouth increased gradually, and the river mouth terrace expanded radially. Furthermore, image analysis of the radar images was applied to estimate the migration speed of the brightness pattern, which is assumed to be a proxy of bottom undulation of the river bed. The migration was observed to be faster when the water level gradient between the river channel and sea increased.
\end{abstract}

Keywords: flushing of river sand bar; remote sensing; X-band radar

\section{Introduction}

Morphological data are essential to evaluating and understanding the long- and short-term behavior of a sandy river. Traditional in situ surveying, such as leveling and echo sounding, provides precise position data at measured points. It is, however, costly, time-consuming, and difficult to collect data during floods, and, therefore, provides only infrequent and low-density measurements. Data collection is limited to fair weather conditions and daytime periods, which makes it difficult to wholly track a sudden event like a flood. In this context, an X-band radar can be used as an alternative to remotely observe the behavior of river morphology. An X-band radar is an imaging radar that is capable of tracking the movements of wave crests over an area spanning several kilometers and has become popular in coastal studies in the last decades [1-3]. X-band radar provides distortionless images of a broad area at intervals of 2-3 s. The intensity of a pixel in the radar image corresponds to the relative amount of backscatter signal of the emitted radar beam reflected from the flood plain, such as vegetation, water surface, etc., and hence it is usable during the night and under slightly rainy and high-wave conditions. However, one defect of the radar system is the difficulty it has in detecting color information: it is difficult to infer the condition of the water surface, existence of suspended materials, vegetation, etc., which can be discriminated by the interpretation of visible images.

Recently, Holman and Haller discussed the various aspects of the different disciplines of nearshore remote sensing in a review article [4]. They compared merits and characteristics of active and passive remote sensors (cameras, radars, lidars, etc.) and platforms (fixed, flying, floating, and orbiting), and concluded that for nearshore oceanographic applications, fixed optical cameras and X-band radars are the most frequently used and best developed. This study demonstrates the potential of land-based $\mathrm{X}$-band radar observation in a drastic developing flood event at a river mouth in Japan.

The River Tenryu flows to the Enshu Coast (lat/long: N-34.6472/E-137.7933). The coast suffers from severe erosion and an enhancement of sediment supply from the catchment is planned by authorities in order to mitigate the erosion. The river basin area is $5090 \mathrm{~km}^{2}$, and the length of the river 
is $213 \mathrm{~km}$. Observation by a land-based X-band imaging radar helps us understand the morphology and hydrodynamics by capturing spatial distributions and temporal variation of water lines of the river channel and coast lines, and wave propagation in the shallow area $[5,6]$.

In this work, morphological changes during a flood event are described from the radar images collected continuously for more than $72 \mathrm{~h}$ from the beginning of the flood, which demonstrates the potential of X-band radar in tracking geomorphological processes during an extreme event. Morphological variations of the area were interpreted from the time-averaged radar images. Brightness patterns in the time-averaged radar images migrated in the down-flow direction during the flood, and image analysis of the pixel intensities was applied to estimate their migration speeds. The migration was faster when the water level gradient between the river channel and the sea level increased, which implies that the time-averaged images captured the migration of the bottom features of the river bed.

Pianica et al. [7] recently reported a video-based observation of bedform deformation of ebb delta over 23 days in the United States. They tracked the migration of bedform features, which was mainly induced by the tidal action under fair conditions and estimated their speed. This study also discusses migration of bedform features, but induced by a river flood, and shows another aspect of morphological dynamics at a river mouth.

\section{Study Area and X-Band Radar Observation}

The radar employed in this study is a conventional incoherent marine $\mathrm{X}$-band radar for commercial use (JMA-3925-9 Japan Radio Co. Ltd. Tokyo, Japan, $3 \mathrm{~cm}$ wavelength, transmitting power $25 \mathrm{kw}$, HH-polarization, radar pulse length $0.08 \mu \mathrm{s}$ ), which is usually installed on fishing boats or ships. The $2.8 \mathrm{~m}$ antenna rotates with a period of approximately $2.6 \mathrm{~s}$ and transmits with a beamwidth of $0.8^{\circ}$ in the horizontal and $25^{\circ}$ in the vertical. The radar is installed on the roof of a sewage plant located on the right side bank close to the mouth of the river as shown in a satellite image in Figure 1a. The measurements started in June 2007 and continued until December 2015.

The echo signals are sampled along the radial direction and then converted to a rectangular image of 1024 pixels in the horizontal and vertical. Each pixel corresponds to a square of length $5.43 \mathrm{~m}$, which is smaller than the theoretical spatial resolution of $7.5 \mathrm{~m}$ of the radar system determined from the pulse length of the emitted beam [3]. A total of 512 radar images captured every $2 \mathrm{~s}$ are processed into time-averaged radar images, an average over $17 \mathrm{~min}$, as shown in Figure 1b. Time-averaged radar images are processed hourly, which enables interpretations of water lines of the river channel, dune locations, shore positions, breaker zones, river plume front formed by the river discharge, etc. $[5,6]$. Qualitative comparison with satellite data shows that the highest echo signals come from solid surfaces such as dunes and the floodplain, etc., which are depicted with bright pixels, and water areas where depths are shallow also return relatively high signals from rippling on the water surface. Smooth sea and river water surfaces return only a small amount of the emitted beam, so they are dark in the time-averaged radar image. The figure also shows the coordinate system used in the study: $x$-coordinate for east-west extent and $y$-coordinate for north-south. The details of radar data processing are described in previous work [3]. 



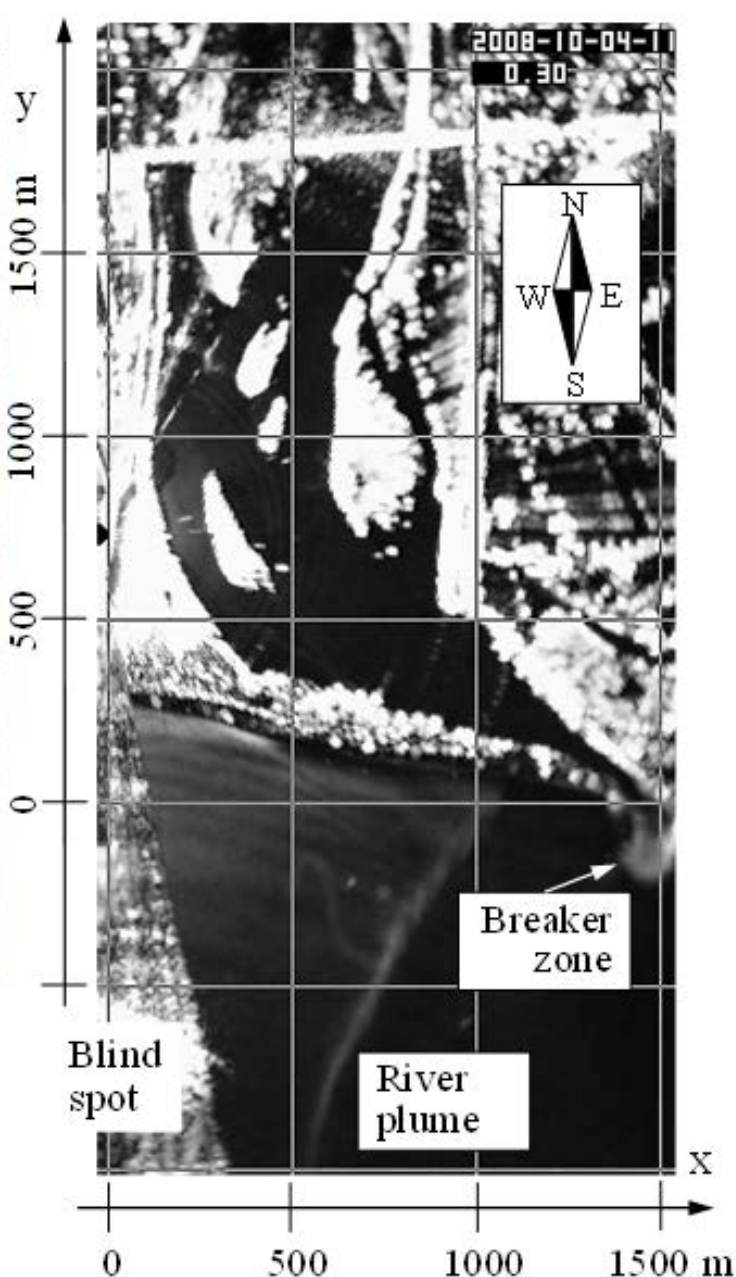

(b)

Figure 1. (a) Satellite visible image of the study area (True color composite display); and (b) time-averaged radar image. Satellite image: Ikonos-2. Acquisition date/time: 4 October 2008, 10:54 JST. Time-averaged radar image: average of images collected from 11:00 JST to 11:17 JST on 4 October 2008. Tide level of Omaezaki: 0.30 m (T.P.).

A Baiu front was active from 10 to 16 July 2010 along the Japanese main island Honshu and delivered heavy rain in the catchment of the River Tenryu. Figure 2 shows the variations of river water levels, tide level, flow rate and rainfall. River water levels in Tokyo Peil (T.P.) were measured at the Kakezuka station, $4 \mathrm{~km}$ from the river mouth in the tidal range, and the Nakanomachi station, $9 \mathrm{~km}$ from the river mouth, and the river flow rate was estimated at the Kashima station, $25 \mathrm{~km}$ from the river mouth. The water level record is missing from 16 h (JST) on 16 July 2010 at the Kakezuka station. The ocean sea level was measured at the Omaezaki tide station, $40 \mathrm{~km}$ to the east of the river mouth. The largest delay of the tidal propagation from the tide station to the river mouth was estimated approximately $5 \mathrm{~min}$ from the records of neighboring tide stations. The rainfall was measured at the Iwata weather observatory, $9 \mathrm{~km}$ to the north east of the river mouth. 


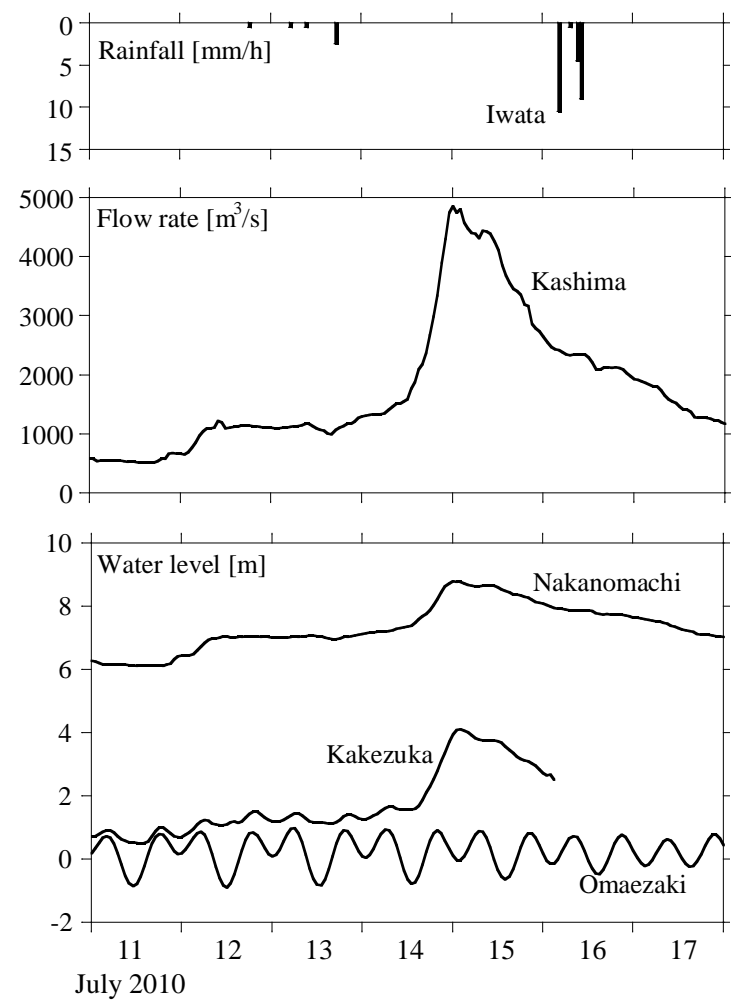

Figure 2. Variations of rainfall (upper panel), estimated flow rate (middle panel), and water levels in the river channel (Nakanomachi and Kakezuka) and sea (Omaezaki, bottom panel), observed during the flood.

According to the Hamamatsu Office of River and National Highway, the maximum amount of water released from the Funagira reservoir, located $5 \mathrm{~km}$ upstream from the Kashima station, was $4400 \mathrm{~m}^{3} / \mathrm{s}$ at $22 \mathrm{~h}$ on 14 July 2010 . Right after this time, the highest water levels were recorded at the Nakanomachi and Kakezuka stations. The return period of a flow rate of $4000 \mathrm{~m}^{3} / \mathrm{s}$ for the River Tenryu is estimated to be approximately 30 years by the Japanese River Bureau. The maximum deviation of the observed tide level from the astronomic tide, which is estimated by the Japan Meteorological Agency, was approximately $0.15 \mathrm{~m}$ during this period. There were short-term rainfalls up to $10 \mathrm{~mm} / \mathrm{h}$ on 18 July 2010, which did not contribute to the flood flow. Significant wave heights measured by a nearby wave station (approximately $5 \mathrm{~km}$ from the river mouth) were almost below $1 \mathrm{~m}$ during the period of interest. The author regards the effect of wind waves as negligible compared to the result of the flood flow. Detailed analyses on radar images for the days from 14 to 16 July during the flood will be described in the following sections.

\section{Morphological Changes during the Flood}

\subsection{Interpretation of Time Averaged Radar Images}

Figure 3a shows the time-averaged radar images for pre- and post- flooding, and Figure $3 \mathrm{~b}$ for even hours during the flood when the river discharge exceeded $3000 \mathrm{~m}^{3} / \mathrm{s}$ for $30 \mathrm{~h}$. The lower portion of each image shows the water level variations measured at the Nakanomachi station in the river and the Omaezaki tide level station. The white vertical line in this lower portion denotes the temporal position in the radar acquisition. As shown in Legends 1 and 2, dunes in the river are named 'Dunes 1 , 2 , and 3 ' in sequence from the river mouth, dunes extending from east to west at the river mouth are labeled 'Sand bar', and a fan-shaped deposition at the river mouth is designated 'River mouth terrace'. 
An animation processed from the time-averaged radar image has been uploaded to YouTube [8] and the results of image interpretation at different stages during the flood are summarized in Table 1.

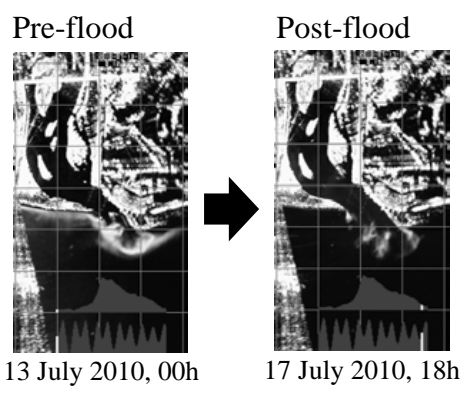

(a)
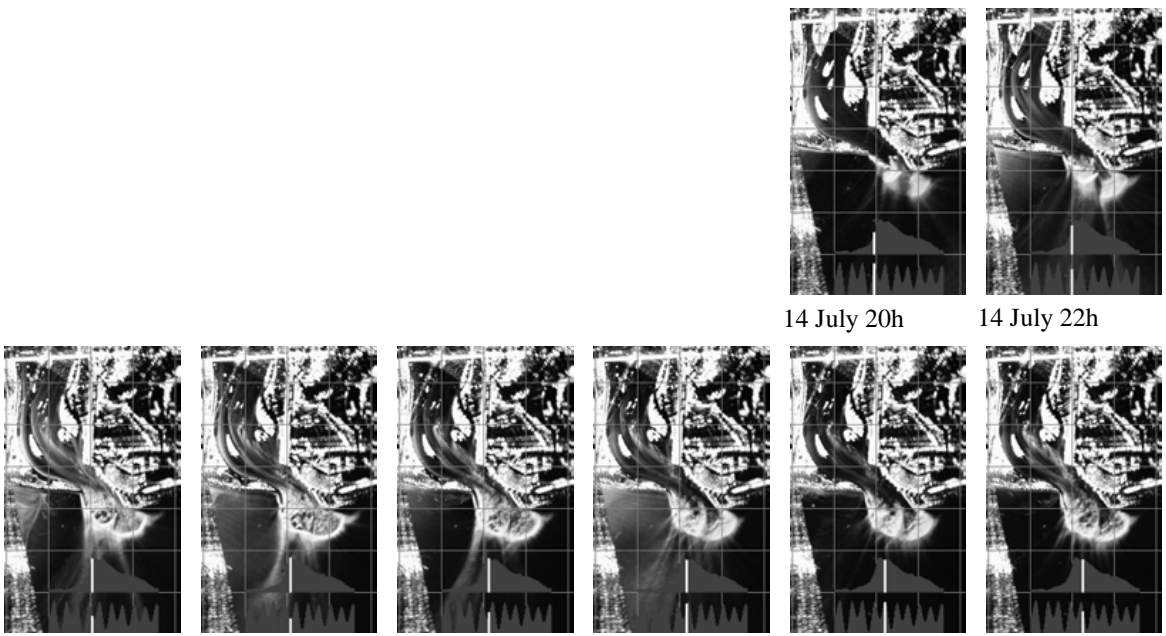

14 July $20 \mathrm{~h}$

14 July $22 \mathrm{~h}$



15 July $02 \mathrm{~h}$
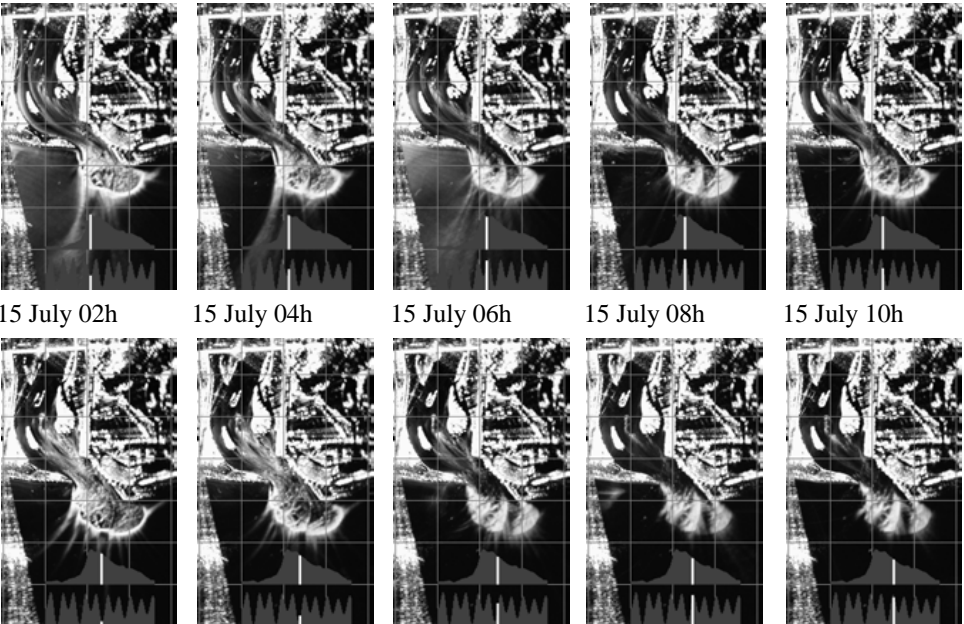

15 July 04h

15 July $06 \mathrm{~h}$

15 July 08h

15 July $10 \mathrm{~h}$

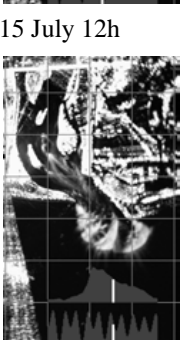

16 July $00 \mathrm{~h}$
15 July $14 \mathrm{~h}$

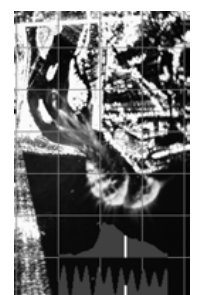

16 July $02 \mathrm{~h}$

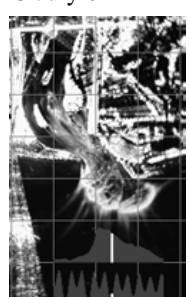

15 July $16 \mathrm{~h}$

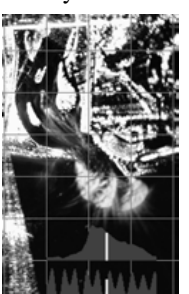

15 July $18 \mathrm{~h}$

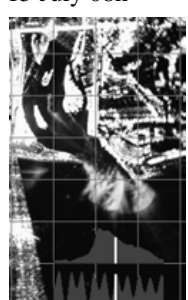

15 July 20h

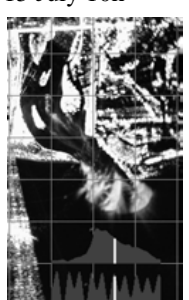

15 July $22 \mathrm{~h}$



(b)

Figure 3. (a) Time-averaged images during the flood. Pre-flood: 13 July 2010, $00 \mathrm{~h}$ JST. Post-flood: 17 July 2010, $23 \mathrm{~h}$ JST. The lower portion of each image shows the water level variations measured at the Nakanomachi station in the river and the Omaezaki tide level station. The white vertical line in this lower portion denotes the temporal position in the radar acquisition; (b) Time-averaged images during the flood. From 14 July 2010, $20 \mathrm{~h}$ to 16 July 2010, $02 \mathrm{~h}$. 
Table 1. Morphological changes during the flood.

\begin{tabular}{|c|c|c|c|}
\hline Time & Flood & Dunes 1,2 , and 3 & Sand Bar and River Mouth Terrace \\
\hline 00 h 13 July 2010 (Figure 3a) & - Pre-flood. & $\begin{array}{l}\text { - Dunes } 1,2 \text {, and } 3 \text { are } \\
\text { clearly observable. }\end{array}$ & $\begin{array}{l}\text { - Tip of the sand bar is located at } x=900 \mathrm{~m} \text {. Width of } \\
\text { the river mouth is approximately } 190 \mathrm{~m} \text {. }\end{array}$ \\
\hline $\begin{array}{l}20 \mathrm{~h}-22 \mathrm{~h} 14 \text { July } \\
\text { (1st row of Figure } 3 \mathrm{~b} \text { ) }\end{array}$ & - Water level is rising. & & $\begin{array}{l}\text { - Ring-shaped river mouth terrace starts to } \\
\text { expand offshore. }\end{array}$ \\
\hline $\begin{array}{l}00 \mathrm{~h}-10 \mathrm{~h} 15 \text { July } \\
\text { (2nd row of Figure } 3 \mathrm{~b} \text { ) }\end{array}$ & $\begin{array}{l}\text { Water level increases rapidly and } \\
\text { reaches the maximum during } \\
\text { the flood. }\end{array}$ & $\begin{array}{l}\text { Dunes } 2 \text { and } 3 \text { are submerged for } \\
\text { approximately ten hours and may } \\
\text { have been eroded actively. }\end{array}$ & $\begin{array}{l}\text { - Sand bar is eroded and the tip shifted to } x=800 \mathrm{~m} \text {. } \\
\text { Width of the river mouth increases to approximately } \\
280 \mathrm{~m} \text {. } \\
\text { Radial development of the river mouth terrace } \\
\text { proceeds offshore from the river mouth. }\end{array}$ \\
\hline $\begin{array}{c}12 \mathrm{~h}-16 \mathrm{~h} 15 \text { July } \\
\text { (3rd row of Figure } 3 b)\end{array}$ & $\begin{array}{l}\text { Water level of the river is decreasing, } \\
\text { but the tide level is close to low tide } \\
\text { and there is still a significant gradient } \\
\text { in water level, which should have } \\
\text { increased the sediment load in } \\
\text { the river. }\end{array}$ & $\begin{array}{l}\text { Dune } 3 \text { is observable when the water } \\
\text { level decreases, whereas Dune } 2 \text { does } \\
\text { not appear, suggesting the lower } \\
\text { portion of the dune is eroded by } \\
\text { the flow. }\end{array}$ & $\begin{array}{l}\text { - Position of the tip of the sand bar remains stagnant. } \\
\text { The fan-shaped river mouth terrace becomes clearly } \\
\text { visible when the tide level descends. At the edge of } \\
\text { the river mouth terrace, several streaks are } \\
\text { extending radially to the offshore, which may be } \\
\text { trace flow. }\end{array}$ \\
\hline $\begin{array}{l}18 \mathrm{~h} 15 \text { July- } 02 \text { h } 16 \text { July } \\
\text { (3rd and } 4 \text { th row of Figure } 3 b \text { ) }\end{array}$ & $\begin{array}{l}\text { Final stage of the flood. Water level is } \\
\text { decreasing. Morphological change } \\
\text { becomes small. }\end{array}$ & $\begin{array}{l}\text { - Upper portion of Dune } 3 \text { appears } \\
\text { above the water. Similar to sand dune } \\
\text { 1, the geometry is unchanged from } \\
\text { the pre-flood state. Relative elevation } \\
\text { of Dune } 1 \text { was high, and it was never } \\
\text { submerged during the flood. }\end{array}$ & \\
\hline 18 h 17 July 2010 (Figure 3a) & - $\quad$ Post-flood. & - Dune 2 is washed away. & \\
\hline
\end{tabular}


Comparing pre- and post-flood time-averaged images shown in Figure 3a, the major changes due to the flood are that dune 2 was totally washed away and the width of the river mouth was widened to approximately $100 \mathrm{~m}$. The configuration of dunes 1 and 3 and the main portion of the sand bar remain almost the same, suggesting that the river channel is not easily erodible even by a 30 year-return-period flood going through the area.

\subsection{Erosion of the Sand Bar during the Flood}

The waterline, boundary between the land and water surface, can be identified from the time-averaged radar images by manual digitization [3]. Based on empirical experiences, the distribution of pixel intensity shows an abrupt change at the waterline, higher brightness for the sand covered surface and darker for the water body. Using this empirical rule, the waterlines along the sand bar at different times have been identified from the time-averaged radar images by manual operation.

Figure 4 shows variation in the east-west position of the tip of the sand bar, with the water level difference between the river water level at the Kakezuka station and the tide level at the Omaezaki station. The variation in the water level difference may be regarded as a proxy of flow velocity change during the flood. The river mouth widened during the flood, as described in Table 1, and this process can also be tracked from the display: when the difference in the water level between the river and sea starts to increase on 14 July 2010, the tip position begins to shift westwards, or erosion starts with a speed of approximately $25 \mathrm{~m} / \mathrm{h}$. After the water level difference reaches a maximum on $15 \mathrm{July} 2010$, the shifting and erosion of the tip of the sand bar has stopped. After this period, variation in the main channel becomes prominent, which will be described in the next section.

\subsection{Migration Speeds of Radar Light-Dark Brightness Patterns along the Channel}

Careful inspection of the sequence of time-averaged radar images and animation introduced above reveals that streaky light-dark patterns migrated downstream in the river channel, especially during the periods when the river water level was descending. As mentioned previously, these light-dark patterns are the result of strong backscattering from the water surface roughness, which becomes larger when the near surface flow is turbulent. The water flow may become turbulent in shallow areas, where active interaction between the water surface and river bottom occurs. Thus, we surmise that migrations of light-dark patterns are proxies of river bed variation during the flood. Unfortunately, exact determination of the origin of this light-dark pattern is difficult since no on-site measurement was done during the flood. To assess this speculation, migration speeds of the patterns were estimated by processing a time-stack image.

Figure 5 shows a time-averaged image on the left and a time stack image on the right. To obtain the time stack image, which has spatial extent in the vertical and temporal extent in the lateral, pixel intensities along the oblique grey bands shown in the time-averaged image, whose width in the lateral or east-west direction is 15 pixels or $81 \mathrm{~m}$, were extracted and stacked in the vertical at specific times. This extraction was repeated for the following time-averaged images and stacking positions shifted in the lateral. In the lower right below the time stack image, the river water level variation measured at Nakanomachi and the tide level at Omaezaki are also shown. 


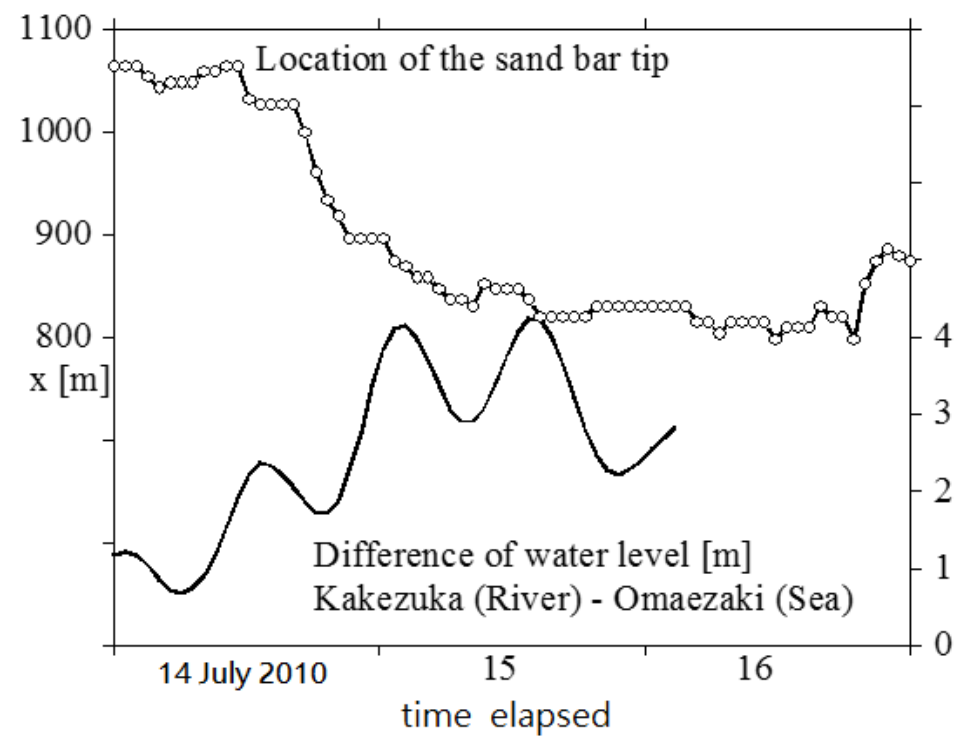

Figure 4. Variation of the east-west location of the tip of the sand bar, and the water level difference between the river and the sea. $x$ denotes east-west coordinate shown in Figure $1 \mathrm{~b}$.

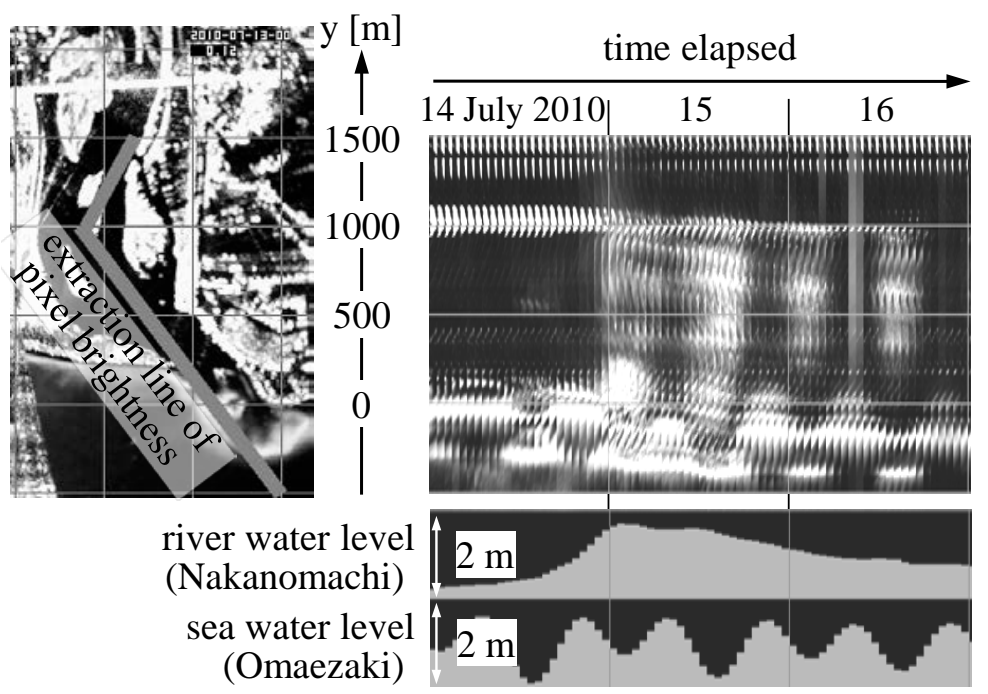

Figure 5. Migration of streaky light-dark patterns downstream in the river channel: Time-averaged radar image (left) and time stack image (right). $y$ denotes north-south coordinate shown in Figure $1 \mathrm{~b}$.

In the time stack, oblique propagations towards the lower right can be seen, which indicate that light-dark patterns in the time-averaged image traveled in the down-flow along the extraction line. This becomes prominent for 15 and 16 July 2010 when the flood was decaying, especially during low tide. The local gradient of the oblique features seems to change with the water level variation.

A PIV (Particle Image Velocimetry)-like method was applied to detect local gradients of the oblique features in the time stack image [9]. First, a $33 \mathrm{~m}$ or 6 pixel-long spatial template extending in the vertical in the times stack image was established at time $t_{0}$. Next, the most similar pattern was found at time $t_{0}+1$, by calculating the correlation coefficient, to estimate the hourly migration distance of the local light-dark pattern. Figure 6 shows the variation of migration speeds averaged over $500 \mathrm{~m}$ in the north-south direction and the difference between the river water level at the Kakezuka station and the tide level at the Omaezaki station. Estimation at some times and locations, mostly when the tide level was high and rainy periods, are missing since the patterns were unclear to establish 
a correlation. We should notice that the velocity estimate here is a one-dimensional assessment: the estimated velocity is the migration speed of the light-dark pattern along the extraction line shown in Figure 5. In other words, an assumption has been made that the light-dark pattern moves mainly along the extraction line.

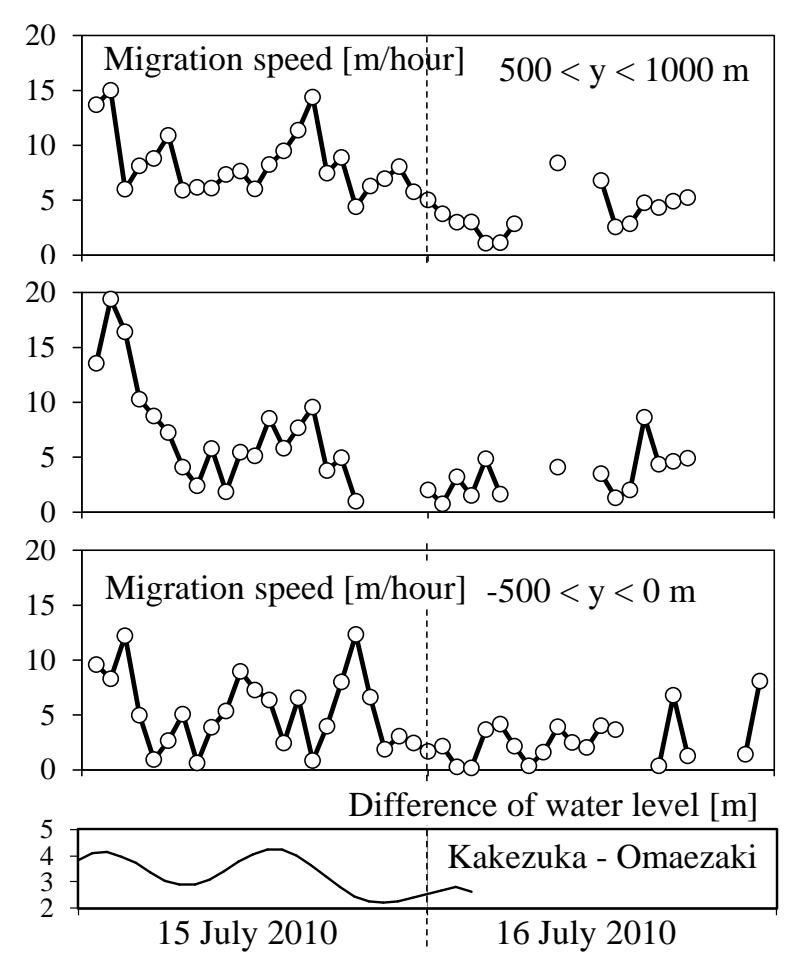

Figure 6. Variation of migration speeds of light-dark patterns in the time-averaged radar image and the water level difference between the river and the sea.

Estimated migration speeds of the light-dark pattern were of the order of $10 \mathrm{~m} / \mathrm{h}(\sim 0.003 \mathrm{~m} / \mathrm{s})$ and varied in accordance with the water level gradient, which supports our speculation, or the proxy hypothesis, that light-dark patterns can be regarded as proxies of river bed variation during the flood.

Gaeuman and Jacobson [10] made measurements on the change of bottom profiles in the Missouri River at a portion where the river width is several hundred meters. During brief water rises with flow rates of $5464 \mathrm{~m}^{3} / \mathrm{s}, 4303 \mathrm{~m}^{3} / \mathrm{s}, 4048 \mathrm{~m}^{3} / \mathrm{s}$, and $2831 \mathrm{~m}^{3} / \mathrm{s}$, they found migration speeds of the bed undulations were in the range of 1 to $6 \mathrm{~m} / \mathrm{h}$, which is of the same order as the results shown above. This further supports our proxy hypothesis.

\section{Concluding Remarks}

A flood event at the Tenryu River mouth was observed with X-band radar. Hourly time-averaged radar images over $72 \mathrm{~h}$ were processed to understand the morphological changes due to the flood. Image interpretation qualitatively described the processes of morphological transitions. The variation of tip location of the sand bar read from the time-averaged radar images shows that the erosion at the sand bar tip occurred mostly before the river water level reached the maximum. PIV-like image analyses were applied to estimate the down-flow migration speed of possible morphological features, which varied in accordance with the water level gradient between the river and the sea.

The estimated migration speeds from the radar may be used in formulae that relate sediment loads to migration rates of river bed undulations to estimate river sediment loads. For example, Gaeuman and Jacobson [10] tried to estimate the bed-load transport using the down-stream propagation speed obtained from the field measurement and correlated with flow velocity. A similar approach may be attempted using the present data; however, this is beyond our scope at this time. 
The results of the field observation demonstrate that an X-band radar is a powerful imaging device to track a flood event in detail and continuously during day- and nighttime periods. Although it cannot detect color information and therefore is hard to infer the condition of the water surface, existence of suspended materials, vegetation, etc., the morphological variation can be assessed robustly throughout an extreme event.

Acknowledgments: The author is grateful for the support provided by Takahashi Ryo, a former graduate student, and Sato Shinji and Tajima Yoshimitsu, the University of Tokyo, for their help with the field observations. This research is supported by the Special Coordination Funds for promoting Science and Technology of Ministry of Education, Culture, Sports, Science and Technology and the River Fund, The Foundation of River \& Watershed Environment Management.

Conflicts of Interest: The author declares no conflict of interest.

\section{References}

1. Bell, P.S. Shallow water bathymetry derived from an analysis of X-band marine radar images of waves. Coast. Eng. 1999, 37, 513-527. [CrossRef]

2. Ruessink, B.G.; Bell, P.S.; Van Enckevort, I.M.J.; Aarninkhof, S.G.J. Nearshore bar crest location quantified from time-averaged X-band radar images. Coast. Eng. 2002, 45, 19-32. [CrossRef]

3. Takewaka, S. Measurements of shoreline positions and intertidal foreshore slopes with X-band marine radar system. Coast. Eng. J. 2005, 47, 91-107. [CrossRef]

4. Holman, R.; Haller, M.C. Remote sensing of the nearshore. Ann. Rev. Mar. Sci. 2013, 5, 95-113. [CrossRef] [PubMed]

5. Takewaka, S.; Takahasi, Y.; Tajima, Y.; Sato, S. Observation of morphology and flow motion at the river mouth of Tenryu with X-band radar. In Proceedings of Coastal Dynamics 2009; Mizuguchi, M., Sato, S., Eds.; World Scientific: Singapore, 2009.

6. Takewaka, S. Visibility of river plume fronts with an X-band radar. J. Sens. 2016. [CrossRef]

7. Pianca, C.; Holman, R.; Sieglea, E. Mobility of meso-scale morphology on a microtidal ebb delta measured using remote sensing. Mar. Geol. 2014, 357, 334-343. [CrossRef]

8. Flood observed at the mouth of Tenryu River. Available online: http://www.youtube.com/watch? $\mathrm{v}=\mathrm{msu}-7 \mathrm{CEHH} \mathrm{I}$ (accessed on 25 December 2015).

9. Elsayed, M.G.; Takewaka, S. Longshore migration of shoreline mega-cusps observed with X-band radar. Coast. Eng. J. 2008, 50, 247-276.

10. Gaeuman, D.; Jacobson, R.B. Field assessment of alternative bed-load transport estimators. J. Hydraul. Eng. 2007, 133, 1318-1319. [CrossRef]

(C) 2016 by the author; licensee MDPI, Basel, Switzerland. This article is an open access article distributed under the terms and conditions of the Creative Commons Attribution (CC-BY) license (http://creativecommons.org/licenses/by/4.0/). 